\title{
Editorial 65
}

\author{
Eric Scerri ${ }^{1}$
}

Published online: 22 June 2020

(c) Springer Nature B.V. 2020

The latest edition of the journal is mostly taken up by a special issue that is dedicated to the 150th anniversary of the periodic table. It is worth noting that this issue has taken shape spontaneously, as a result of independently contributed articles, and not following a call for papers. The International Year of the Periodic Table, or IYPT 2019, was highly successful in bringing renewed attention to chemistry from the general public and experts alike. Many conferences were held and fortunately they all took place before the current pandemic brought international travel to a complete standstill. This has of course represented an enormous contrast for many of us. ${ }^{1}$

Nevertheless, readers can now benefit from six interesting articles on the periodic table from a wide variety of perspectives. Brad Wray, an American philosopher of science based in Denmark, along with his colleague Line Andersen, open the special issue by supporting Thomas Kuhn's account of scientific change. In this instance the authors argue that the discovery of the elements neon and hafnium, that took place thirty years apart, represent an example of chemists working in different worlds as a result of a scientific revolution-the discovery of atomic number.

Haresh Lalvani is an architecture professor based in New York with a life-long interest in the periodic table. Drawing on his design skills he has invented what he terms a fourdimensional periodic table that he presents here for the first time.

Chris Campbell and Karolina Pulkkinen, two UK based historian-philosophers, take up the challenge of just how Mendeleev arrived at various numerical values for the properties of his first three predicted elements of gallium, germanium and scandium. The authors proceed to give what I believe may be the best explanation yet for the kinds of interpolation that Mendeleev conducted among the numerical values of the surrounding elements.

Rene Vernon is an Australian author who is a frequent contributor to Wikipedia on matters connected with the elements and the periodic table. His article proposes a weakening of the almost universal classification of elements into the three categories of metals, metalloids and non-metals. Vernon believes that it is more instructive to classify elements into four categories of metals, and similarly, four categories of non-metals.

\footnotetext{
${ }^{1}$ For example, I gave a total of 10 invited lectures in overseas locations on the periodic table during 2019. These included visits to St. Petersburg, Tartu, Puebla, Malta, Turin, Auckland, Christchurch, Qatar, London, Umea and Antwerp in addition to various US institutions. In 2020 I have not yet given a single public lecture.
}

Eric Scerri

scerri@chem.ucla.edu

1 Department of Chemistry and Biochemistry, UCLA, Los Angeles, CA 90095, USA 
Julio Gutierrez from Cusco in Peru was the organizer of the third international conference on the periodic table that took place in $2012 .^{2}$ His article in this issue provides a mathematical analysis of the periodic table that highlights the doubling of period lengths, which the author attributes to a "binodic function".

Kouichi Hagino and Yoshiteru Maeno are from Kyoto University in Japan. Their contribution presents a three-dimensional periodic table of the protons of the elements designed in such a way as to emphasize the occurrence of nuclear shell closure with spherical nuclei and those nuclei that depart from shell closure with nuclear deformation. The special issue closes with John Emsley's review of the second edition of my 2007 book on the periodic table.

The first of the remaining three varia papers is by Elena Ghibaudi, Luigi Cerruti and Giovanni Villani from Italy who provide an in-depth, and historically nuanced, analysis of the often-confused concepts of molecular structure, molecular shape and molecular topology.

Keith Taber from Cambridge in the UK provides a welcome excursion into the relationship between philosophical issues in chemistry and how they relate to his specialty of chemical education. Here he discusses and criticizes the manner in which the current English National Curriculum sets out the teaching of chemical reactions by stipulating that they take place in only three different ways, namely proton transfer, electron transfer or electron sharing.

Finally, Hiteshi Tandon, Tanmoy Chakraborty and Vandana Suhag, from India, survey the concept of electronegativity, which has been defined and measured in a multitude of ways over the years. The authors aim is to simplify the concept by utilizing a scale of electronegativity based on a universal atomic nucleophilicity index scale that was recently proposed by the lead author. In the current paper the authors compute their brand of electronegativity for 103 elements and show how this data reflects a high degree of chemical periodicity.

In closing, I would just mention that after 23 years of continuous ISPC conferences, this year's event that was due to be held in Buenos Aires, had to be cancelled. Assuming that things go back to normal in due course, the would-be Argentinian organizers have agreed to host the next meeting in the summer of 2021. Until then we luckily have books and journals to keep things going before our annual in-person meetings will hopefully be resumed.

Publisher's Note Springer Nature remains neutral with regard to jurisdictional claims in published maps and institutional affiliations.

\footnotetext{
${ }^{2}$ The proceedings of this conference have been published, as have those of the other three international conferences on the periodic table. The Cusco meeting proceedings is, E.R. Scerri, G. Restrepo (eds.), Mendeleev to Oganesson, Oxford University Press, New York, 2018.
} 